\title{
ATORES SOCIAIS E FORMULAÇÃO: o caso da influência da ONG Igualdade - RS na construção de ações para a proteção de direitos
}

Drielli Duarte ${ }^{1}$

\section{Resumo:}

O presente trabalho tem por objetivo mostrar a influência de uma Organização Não Governamental (ONG) na formulação de políticas públicas elucidando como se relaciona com o Estado. Os principais conceitos que utiliza são os de atores sociais, de políticas públicas e de gênero. O objeto empírico de estudo deste trabalho é a ONG Igualdade - RS voltada para a população de travestis e transexuais. A fim de verificar a influência da ONG na formulação de ações para a proteção de direitos, serão abordadas duas ações implementadas para a população de travestis e transexuais, quais sejam a Carteira de Nome Social e a Ala do Terceiro do "H", que é uma ala especial para as travestis, transexuais e gays criada no Presídio Central de Porto Alegre.

Palavras-chave: Políticas públicas, atores sociais, terceiro setor, ONG, gênero.

\begin{abstract}
:
The paper aims to show the influence of a non-governmental organization (ONG) on the formulation of public policies and its relationship with the government. It employs the concepts as social actors, public policies and gender. In order to identify ONG Igualdade-RS's influence on policies to ensure rights, it analyses two acts implemented to protect transvestites and transsexuals, the Carteira de Nome Social and the Ala do Terceiro do "H", which is a special section for transvestites, transsexuals and gays created at Presidio Central de Porto Alegre (prision).
\end{abstract}

Keyword: Public policies, social cluster, third sector, ONG, gender.

\footnotetext{
${ }^{1}$ Bacharela em Políticas Públicas pela Universidade Federal do Rio Grande do Sul. Atualmente é Coordenadora da "Casa da Cidadania da Grande Mathias Velho e Harmonia", projeto social da Secretaria Municipal de Segurança Pública e Cidadania do Município e Canoas e mestranda em Ciências Sociais na Pontifícia Universidade Católica do Rio Grande do Sul. E-mail: drielli.duarte@gmail.com.
} 


\section{Introdução}

O presente trabalho aborda a relação entre as instituições denominadas de Organizações Não Governamentais e Políticas Públicas, na fase de formulação da política. Ou seja, busca elucidar, em que medida, tais instituições influenciam ou participam da formulação de políticas públicas e como se dá essa influência ou participação nessa fase inicial do ciclo das políticas públicas. Para tanto, será feita uma revisão acerca das fases constitutivas de uma política pública, com especial enfoque na fase de formulação, que quase sempre é pensada como um processo que diz respeito ao Estado, sem atentar para o fato de que existem atores chave em muitas políticas formuladas. Nesse trabalho será mostrado o papel da ONG Igualdade - Associação de Travestis e Transexuais do Rio Grande do Sul na formulação de políticas públicas, abordando duas ações que essa ONG já formulou e hoje se encontram implementadas, que é a Carteira de Nome Social e uma Ala Especial para o Público de Travestis e Gays no Presídio Central de Porto Alegre. Por se tratar de uma ONG de Travestis e Transexuais, é fundamental abordar a questão de políticas públicas e gênero.

Por este trabalho tratar de uma ONG, é necessário entendermos como surgiram as ONGs no âmbito da sociedade civil, como foi esse processo social. Sendo assim, ainda na introdução, serão feitos alguns comentários sobre a sociedade civil e sua constituição.

Este trabalho está dividido em três blocos, o primeiro que vai trazer uma revisão na literatura sobre Políticas Públicas, Formulação de Políticas e Atores Sociais, pois o tema central do trabalho faz referência aos atores sociais na fase primordial das políticas públicas, ou seja, na formulação. O segundo bloco vai trazer o objeto de estudo desse trabalho, que é a ONG Igualdade RS, e como foi dito anteriormente será tratada brevemente a questão de gênero, por se tratar de uma ONG de Travestis e Transexuais. O terceiro bloco mostrará a importância da ONG Igualdade - Associação de Travestis e Transexuais do Rio Grande do Sul na construção de ações para proteção de direitos, que é resultado de entrevistas aplicadas em pessoas que estiveram envolvidas na construção destas ações e abordará também a relação da sociedade civil com o Estado, mostrando a relação extremamente complexa entre essas duas instâncias.

O presente trabalho pode ser considerado de cunho exploratório, não apresentando hipótese em sua estrutura. Dessa maneira, pretende descrever a influência da ONG Igualdade RS na construção de ações para a proteção de direitos, ou seja, das duas ações citadas acima, a Carteira de Nome Social (CNS) e a Ala Especial no Presídio Central de Porto Alegre. 


\section{A sociedade civil}

O conceito de sociedade civil surgiu no século XIX nos países da Europa e Estados Unidos, este conceito era um conceito dualista que separava a sociedade da economia, Gramsci se referia a uma superestrutura política que estava fora da superestrutura econômica, na primeira superestrutura estava à sociedade política e a sociedade civil (COUTINHO, 2007). O conceito ressurge novamente no final do século XX, mas, em primeiro lugar,

(...)diferentemente do início do século XIX, o mercado entendido como a esfera das atividades econômicas privadas também se diferencia da sociedade civil. Em segundo lugar, o conceito de sociedade civil reaparece para explicar os processos sociais que estavam ocorrendo nos países da Europa do Leste e nas sociedades latino-americanas (ARATO, 1981; COHEN \& ARATO, 1992; KEANE, 1988a; 1988b; 1998; HABERMAS, 1995 apud AVRITZER, 2012, p. 384).

Segundo Cohen (2003) a contribuição mais importante do autor foi contemplar a sociedade civil ao mesmo tempo como campo simbólico e como conjunto de instituições e práticas. Dessa maneira, a dimensão cultural da sociedade civil não se estabelece de maneira natural, nem é algo dado, ela é antes um lugar de reivindicação social. Ainda de acordo com Cohen (2003), uma segunda contribuição importante foi a de Touraine, Melucci e outros que:

(...)enfatizaram o aspecto dinâmico, criativo e contestador da sociedade civil - a visão das associações informais e dos movimentos sociais como distintos das associações e instituições voluntárias mais formalizadas e das organizações de classe (partidos, sindicatos) (TOURAINE, 1981; MELUCCI, 1985:798-816; 1980; COHEN e ARATO, 1992:492-564 apud COHEN, 2003, p.425).

Cohen (2003), ainda acrescenta que o reconhecimento desses aspectos dinâmicos nos permite considerar uma possível consequência que acarretaria em a sociedade civil e a sociedade política serem alvos de lutas pela democratização.

O reconhecimento dessa dimensão nos permite articular e transitar entre duas perspectivas: a sociedade civil como fonte dinâmica e inovadora para a tematização de novos problemas; formulação de novos projetos; criação de novos valores e novas identidades coletivas; e a sociedade civil como autonomia cívica institucionalizada. Permite também considerar que, por sua capacidade dinâmica (ação coletiva), o formato institucional da sociedade civil e da sociedade política pode se tornar alvo de lutas pela democratização (COHEN, 2003, p.425).

No Brasil, o conceito de sociedade civil ingressa no debate acadêmico e político junto com o processo de democratização. Na América Latina, surgiu como um conceito tripartite, adaptado às formas de diferenciação entre o mercado, Estado e sociedade que se consolidou nessa região no século XX (AVRITZER, 2012), de modo que

(...) é importante salientar que o aparecimento da sociedade civil aconteceu junto com o desenvolvimento do moderno Estado territorial soberano. Em outras palavras, 
foi a vinculação do Estado ao direito e o desenvolvimento da soberania e do constitucionalismo jurídico interno que permitiram o surgimento do modelo tripartite (COHEN, 2003, p.423)

A primeira razão para a emergência da sociedade civil no Brasil, conforme o pesquisador Leonardo Avritzer (2012), foi à consequência de inúmeros processos. O primeiro se refere à urbanização intensa nos anos 1960 e 1970, que moveu as pessoas do campo para a cidade, causando os problemas societários mais básicos. Assim,

o país passou por um dos processos de urbanização mais rápidos da história, sendo em grande parte um país rural na década de 1940 e passando a ter mais de $80 \%$ de sua população vivendo em cidades no final do século XX (SANTOS, 1987). No processo de deslocamento do campo para a cidade, a população de baixa renda foi despojada de direitos e alocada nas grandes capitais em lugares com pouco ou sem nenhum tipo de serviço público. A organização dos pobres brasileiros para lutar por serviços públicos é uma das origens da sociedade civil brasileira (AVRITZER, 2012, p.386).

A segunda razão que levou à emergência do conceito social no Brasil foram as características do processo de modernização econômica do país, "que transformou as políticas de planejamento urbano, saúde e educação em questões tecnocráticas" (ESCOREL, 1998 apud AVRITZER, 2012, p.386).

Por fim, a terceira foi a "oposição dos setores liberais e de classe média à ausência de regras e accountability nos processos políticos e civis, que transformaram a Ordem dos Advogados do Brasil (OAB) em um dos principais grupos de oposição ao autoritarismo" (AVRITZER, 2012, p.387) portanto,

(...) o aprofundamento democrático que teve lugar durante e após o processo de elaboração da Constituição, e a forma como as reformas neoliberais interagiram com as responsabilidades dos atores da sociedade civil nas políticas públicas. É a partir do resultado dessa interação que diferentes padrões de relações entre Estado e sociedade civil surgiram (AVRITZER, 2012, p.386).

A sociedade civil, segundo Cohen (2003), além de ser uma esfera diferente do Estado e da Economia, ela possui três parâmetros distintos: pluralidade, publicidade e privacidade. O conceito de pluralidade diz respeito à associação voluntária, que incluía as interações face a face e as organizações nacionais baseadas na iniciativa de grupos locais (COHEN, 2003), publicidade referia-se às reuniões públicas e privacidade dizia respeito à autonomia do indivíduo, institucionalizada em leis.

As novas tecnologias de comunicação permitem novas formas de articulações sociais e de contestação política, facilitando novas formas de ações, assim como a mobilização 
extremamente rápida de pessoas de locais diferentes. A partir dessa inovação tecnológica, as organizações internacionais e o Estado modificaram seus procedimentos institucionais.

As novas tecnologias de comunicação também repercutiram na publicidade, com a modernização e surgimento de novos canais de comunicação, como a televisão a cabo ou por satélite e a criação dos noticiários globais onde são exibidas 24 horas, acontecimentos do mundo inteiro, segundo a autora Jean Cohen (2003, p. 438), essas novas tecnologias se tornam veículos de disputa pela influência na "opinião pública mundial".

Na privacidade não foi diferente, valores que antes eram intangíveis passaram por transformações significativas. A instituição família é um exemplo dessa transformação, na medida em que as mulheres, antes submissas ao marido, vistas como dona de casa, responsável pela criação dos filhos, passou a ter personalidade jurídica, ganhando dessa maneira autonomia, respeito e os mesmos direitos que os homens sempre tiveram. A luta da mulher pela igualdade de gênero, certamente é uma das transformações mais importantes e que interferiu, impactantemente no conceito de privacidade, conceituado anteriormente.

Cabe ainda ressaltar uma importante contribuição de Touraine (1981), que os movimentos sociais são vistos como um importante ator coletivo nas transformações da sociedade civil, pois é através deles que as sociedades se renovam, não só a sociedade, mas todo o sistema, visto que a sociedade é entendida como uma esfera separada do Estado e economia, conforme Cohen (2003). Touraine (1981) defende que a sociedade civil resulta dos movimentos sociais e não o oposto, para esse autor, os movimentos sociais nasceriam na sociedade civil, portadores de uma nova identidade social, instigariam a mudança das orientações valorativas, ou seja, os movimentos sociais tentariam quebrar antigos valores culturais, uma mudança cultural sediada na sociedade civil.

\footnotetext{
A ideia de sociedade recebe um significado velado: em vez de ser definida por instituições e/ou por um poder central, e levando em conta que certamente não se pode mais defini-la por valores comuns ou regras permanentes de organização social, a sociedade aparenta ser um campo de debates e conflitos em que está em jogo o uso social dos bens simbólicos produzidos em massa por nossa sociedade pós-industrial (TOURAINE apud ALEXANDER, 1997, p.16).
}

No Brasil, os movimentos sociais tiveram um importante papel na luta não só pelo fim da ditadura, mas também por diversas políticas sociais que se estruturaram a partir de demandas dos movimentos sociais formuladas, após esse momento na história surgiram outras formas de organização popular, mais institucionalizadas, como os Fóruns Nacionais de Luta 
pela Moradia, pela Reforma Urbana, o Fórum Nacional de Participação Popular etc, (GOHN, 2011).

Nos anos de 1990 o movimento dos homossexuais ganhou força e foram às ruas, organizando passeatas e protestos. Nesse período as ONGs passaram a ter muita força.

\begin{abstract}
Aliás, as ONGs passaram a ter muito mais importância nos anos 1990 do que os próprios movimentos sociais. Trata-se de ONGs diferentes das que atuavam nos anos 1980 junto a movimentos populares. Agora são inscritas no universo do terceiro setor, voltadas para a execução de políticas de parceria entre o poder público e a sociedade, atuando em áreas onde a prestação de serviços sociais é carente ou até mesmo ausente, como na educação e saúde, para clientelas como meninos e meninas que vivem nas ruas, mulheres com baixa renda, escolas de ensino fundamental etc (GOHN, 2011, p. 343).
\end{abstract}

Atualmente tanto os movimentos sociais quanto as ONGs, utilizam as redes sociais como instrumento de mobilização e empoderamento da sociedade civil. Hoje é possível se organizar nacionalmente e até mesmo internacionalmente através destas redes. As organizações da sociedade civil ganharam mais força e visibilidade através desses mecanismos modernos.

\begin{abstract}
A meu ver, a rede é uma nova forma de pluralidade que torna possível uma nova forma de conexão social, novas formas de ação coletiva e uma "solidariedade entre estranhos" mais ampla que as anteriores. Não me refiro à "ação coletiva" ou à conexão realizada unicamente pela internet, como uma campanha por correio eletrônico ou as conversas em salas de bate-papo19. Estou pensando na articulação de grupos locais que se inter-relacionam por intermédio da rede virtual de computadores e se comunicam em parte através da nova mídia eletrônica. É essa combinação que constrói um todo maior que a soma de suas partes (COHEN, 2003 p. 435).
\end{abstract}

\title{
Proposta metodológica
}

Para desenvolver esse trabalho foi utilizado o método qualitativo de pesquisa que se justifica, tendo em vista seu caráter exploratório (MALHOTRA, 2006; GIL, 1999; ZIKMUND, 2006). Gil (1999) explica que os dados obtidos através de pesquisa qualitativa não são possíveis de serem generalizados, considerando o número reduzido de entrevistados, que oferecem informações que estarão apenas acrescentando conhecimento ao pesquisador sobre o tema. Trujillo (2003) em concordância com Gil (1999) comenta que a partir de uma pesquisa qualitativa o autor obtém uma maior profundidade do assunto e junto a Malhotra (2006), ressalta que se a necessidade é obter uma melhor compreensão e entendimento de determinado problema, aconselha-se o uso da vertente qualitativa. 
Foram utilizadas entrevistas semiestruturadas na pesquisa de campo, a fim de entender e explorar com devido rigor metodológico a influência da ONG Igualdade RS na formulação de políticas públicas.

Assim, foram feitas sete entrevistas, todas gravadas, e com total consentimento dos entrevistados que assinaram um termo de autorização de gravação de áudio. Por direitos assegurados aos entrevistados e por questões éticas legais, não serão citados os nomes dos entrevistados, somente as iniciais do nome.

\title{
Políticas públicas, formulação e atores sociais
}

As políticas públicas como área de conhecimento e disciplina acadêmica tiveram seu surgimento nos EUA em 1950, com um caráter voltado mais para a produção/ação dos governos do que com o Estado como era a preocupação na Europa nessa época, ela nasce como uma subárea da ciência política.

Não há uma única definição do que sejam políticas públicas, pois seu campo extremamente multidisciplinar dificulta resumirmos as políticas públicas em um único conceito. A definição mais conhecida é a de Lasswell (1936) que faz um questionamento sobre as decisões e análises sobre políticas públicas, perguntando o porquê, que diferença faz e quem ganha o que com essas políticas.

Celina Souza, uma importante estudiosa do campo de públicas, afirma que:

\begin{abstract}
...Pode-se, então, resumir política pública como o campo do conhecimento que busca, ao mesmo tempo, "colocar o governo em ação" e/ou analisar essa ação (variável independente) e, quando necessário, propor mudanças no rumo ou curso dessas ações (variável dependente). A formulação de políticas públicas constitui-se no estágio em que os governos democráticos traduzem seus propósitos e plataformas eleitorais em programas e ações que produzirão resultados ou mudanças no mundo real (SOUZA, 2006, p. 26).
\end{abstract}

A definição mais clássica sobre política pública continua sendo a de Theodore Lowi (1972). De acordo com o autor, as políticas públicas podem ser: distributivas, constitutivas, regulatórias e redistributivas. As distributivas são aquelas que alocam bens e serviços a determinadas frações da sociedade, através de recursos provenientes da coletividade como um todo. As políticas constitutivas são as normas e regras pelas quais as demais políticas públicas devem seguir ou conter. As regulatórias são aquelas que estabelecem obrigatoriedade, condições por meio das quais podem e devem ser realizadas determinadas atividades. As políticas redistributivas são aquelas que distribuem bens e serviços a parcelas particularizadas 
da população, através de recursos oriundos de outros grupos específicos, essas políticas normalmente têm um caráter conflituoso.

A política pública é dividida, grosso modo, em três ciclos: formulação, implementação e avaliação. Essas etapas podem-se dividir indefinidamente em subetapas. Schmidt (2008) define cinco fases distintas: percepção e definição de problemas, inserção na agenda política, formulação, implementação e avaliação.

A primeira e segunda fase pode ser definida como a formação da agenda e elaboração da demanda. Kingdon (1984) foi o autor que melhor trabalhou essas duas primeiras fases do ciclo, a formação da agenda (agenda-setting) e a especificação de alternativas (policy formulation). $\mathrm{O}$ autor se preocupou em responder à seguinte pergunta: como uma determinada ideia entra para a agenda dos formuladores de políticas e se transformam em políticas públicas? Para Capella (2005, p.3), uma

(...) questão passa a fazer parte da agenda governamental quando desperta a atenção e o interesse dos formuladores de políticas. No entanto, dada a complexidade e o volume de questões que se apresentam a estes formuladores, apenas algumas delas são realmente consideradas num determinado momento.

Essas ideias, que são consideradas entre um leque de opções, definem o que Kingdon (1984) chama de agenda decisional e a partir da qual podem se transformar em política. Kingdon (1984) também afirma que a mudança na agenda se dá através da convergência de três fluxos: problemas (problems), soluções ou alternativas (policies) e políticas (politics).

A etapa das políticas comporta uma 'sub-etapa' inicial nomeada como de formulação de políticas públicas, quando se busca construir o desenho para implementação futura da ideia escolhida na agenda. A solução ou alternativa escolhida passa a ser detalhada e então se estabelece juridicamente e administrativamente a política.

Esse é o momento onde deve ser definido qual é o objetivo da política, quais serão os programas desenvolvidos e as metas almejadas, o que significa a rejeição de várias propostas de ação. Certamente essa escolha, além de se preocupar com o posicionamento dos grupos sociais, necessita ser feita ouvindo o corpo técnico da administração pública, inclusive no que se refere aos recursos - materiais, econômicos, técnicos, pessoais, dentre outros - disponíveis (CARVALHO, 2008, p. 12).

A quarta etapa é constituída pela implementação de políticas públicas, que é a etapa onde o planejamento e burocracia viram atos, esse é o momento onde o corpo técnico de fato viabiliza a política, existem dois modelos de implementação, o modelo top-down (de cima 
para baixo) e o modelo bottom-up (de baixo para cima), esses modelos são definidos conforme Carvalho (2008, p.16) como:

\begin{abstract}
O modelo de Cima para Baixo representa um modelo centralizado, onde apenas um número muito pequeno de funcionários participa das decisões e opina na forma da implementação das Políticas Públicas. Ele reflete uma concepção hierárquica da administração pública, segundo a qual a decisão tomada pela administração pública seja acatada e cumprida pelos demais envolvidos, sem questionamentos. Já o modelo de Baixo para Cima é caracterizado pela descentralização. Ou seja, ele supõe a participação dos beneficiários ou do usuário final das políticas em questão. Ele representa uma perspectiva participativa das Políticas Públicas, o que é possível pelo contato direto do cidadão com o aparato da administração pública. Os beneficiários são chamados a participar.
\end{abstract}

Por fim, a quinta e sexta fases do ciclo de políticas públicas consistem respectivamente no acompanhamento e avaliação da política. $\mathrm{O}$ acompanhamento nada mais é do que como o próprio nome já diz, a supervisão das políticas implementadas ou em fase de implementação, com o intuito de verificar possíveis problemas na execução da política e apontar possíveis soluções/alternativas/correções. A avaliação de políticas públicas é uma fase que se distingue da anterior por ser realizada apenas após a execução da política com o intuito de ver os resultados alcançados, o impacto ou as transformações ocorridas, dependendo do tipo de avaliação que será realizada.

\title{
Formulação de políticas públicas e atores sociais
}

A partir do momento em que uma determinada situação é vista como um problema, ela pode ou não ser inserida na agenda governamental. Se ela for inserida na agenda governamental se faz necessário definir as linhas de ação que serão adotadas para solucionar esse problema. Porém esse processo, denominado de formulação de políticas públicas, não é tão simples e pacífico como aparenta ser, pois diferentes grupos e atores sociais terão opiniões divergentes sobre essa formulação. Alguns acharão que essa ação pode ser prejudicial, outros irão concordar, criando uma arena decisória.

O modelo de multiple strems, é muito elucidativo sobre o processo de formulação de políticas. Segundo o modelo existiriam três fluxos no âmbito das políticas: problems (problemas), policies (soluções ou alternativas) e politics (políticas).

No primeiro fluxo, problems, algo se torna problema quando chama à atenção dos formuladores de políticas. Existem três mecanismos que podem tornar uma questão em problema. Isso acontece primeiramente quando os indicadores (sociais ou econômicos) encontram-se com alguma deficiência, necessitando de uma resolução, essa situação pode vir 
a chamar a atenção dos formuladores de políticas. O segundo grupo de mecanismos são os eventos, símbolos e crises (CAPELLA, 2005), quando algum evento, catástrofe de grande magnitude acontece e acaba por chamar a atenção dos fazedores de políticas. O terceiro mecanismo é o feedback, que é realizado em programas ou políticas em implementação, ouvidorias, reclamações ou futuras reclamações de servidores e cidadãos, podem elevar um problema rapidamente na agenda governamental.

Do ponto de vista da estratégia política, a definição do problema é fundamental. A forma como um problema é definido, articulado, concentrando a atenção dos formuladores de política pode determinar o sucesso de uma questão no processo altamente competitivo de agenda-setting, no qual diversas outras questões estão colocadas, aguardando a atenção destes formuladores (CAPELLA, 2005, p. 5).

No segundo fluxo traduzido como soluções ou alternativas (policies), o modelo de multiple strems faz uma analogia ao processo biológico de seleção natural, do mesmo jeito que as moléculas flutuam no que os biólogos chamam de "caldo primordial”. Kingdon (1984) entende que as ideias são geradas em comunidades e flutuam em um "caldo de políticas" (CAPELLA, 2005), onde algumas ideias sobrevivem, outras são transformadas e algumas descartadas. Nesse processo competitivo de ideias, as que têm maior viabilidade financeira (menor custo) ou técnica, normalmente se salvam. As comunidades que foram citadas no parágrafo anterior se referem ao termo policy communities, que foi traduzido como comunidades geradoras de alternativas, essa comunidade é composta por: pesquisadores, acadêmicos, parlamentares, assessores, líderes comunitários, todos que se preocupem com uma determinada área (policy area).

O terceiro fluxo é compreendido como Política (politics), esse fluxo independe dos problemas ou alternativas disponíveis, a política tem sua própria dinâmica onde as coalizões são construídas a partir de processos de barganha. Nesse fluxo existem três elementos que são considerados como tendo influência sobre a agenda-setting. O primeiro é o que Kingdon (1984, p. 358) chama de "humor nacional", quando um grupo de pessoas compartilha das mesmas ideias em um determinado período de tempo.

A percepção de um humor favorável faz os participantes se sentirem estimulados com certas ideias, ou desestimulados com outras. O segundo elemento é compreendido pelas forças políticas organizadas, que são exercidas normalmente pelos grupos de pressão. Esses grupos podem estar em consenso ou em conflito, cabe aos formuladores de políticas avaliarem se o ambiente é propício ou não para uma mudança. $O$ terceiro fator são as mudanças no próprio governo, mudança de atores chave que exerciam determinado controle 
ou davam atenção para determinada ideia, mudança de chefia nas empresas públicas, mudanças no congresso, entre outras, essas mudanças podem desencadear que uma ideia seja descartada ou que novas ideias germinem na agenda-setting.

Enfim, a convergência desses três fluxos é o que determina a mudança na agenda governamental e faz com que os formuladores de políticas deem atenção a uma determinada ideia e a transforme em uma política pública.

\begin{abstract}
Mudanças na agenda acontecem, portanto, quando os três fluxos são unidos, processo denominado por Kingdon (2003, p. 172) como coupling. O coupling, ou a junção dos fluxos, por sua vez, ocorre em momentos em que as policy windows se encontram abertas. Vimos que estas janelas se abrem, sobretudo, a partir dos fluxos de problemas e políticas. No interior destes dois fluxos, alguns eventos acontecem de forma periódica e previsível, como nas situações de mudanças no governo (transição administrativa, mudanças no Congresso, mudanças na presidência de estatais) e em algumas fases do ciclo orçamentário (nos momentos de inclusão de propostas, por exemplo). Outros eventos - ou janelas - se desenvolvem de maneira imprevisível. Assim, a oportunidade de mudança na agenda pode ser dar tanto de forma programada quanto de maneira não previsível (CAPELLA, 2005, p. 11).
\end{abstract}

A questão dos atores sociais também é abordada por Kingdon (1984). Para ele existem dois grupos, os atores visíveis e os participantes invisíveis. Os primeiros detêm a atenção da mídia e do público, como os chefes de estado, os parlamentares, diretores de empresas públicas (que são nomeados pelo chefe de estado). Os atores invisíveis se referem principalmente às comunidades onde as ideias são geradas. São exemplos de participantes invisíveis: pesquisadores, funcionários públicos, grupos de pressão, etc. O primeiro grupo, segundo o autor, tem maior influência sob a mudança na agenda governamental, já o segundo grupo é mais influente nas alternativas e implementações das ideias.

Podemos perceber que os atores sociais exercem um papel importante no que diz respeito à formulação de políticas públicas, pois são eles os principais responsáveis pelas ideias ascenderem à agenda governamental. São eles que dão vida a essas ideias. Os atores sociais são a peça chave da formulação e até mesmo implementação da política. $\mathrm{Na}$ terminologia do desenvolvimento local, os atores são os agentes sociais e econômicos, indivíduos e instituições, que realizam ou desempenham atividades, ou, então, mantém relações num determinado território.

Como foi abordada na introdução, a sociedade civil é o lugar por excelência dos atores sociais. Foi a partir da separação entre a sociedade, Estado e economia que foi possível perceber as diferentes dinâmicas e atores que ali atuavam e principalmente, a maneira que eles atuavam. Existem três tipos de atores, os atores sociais, os estatais e os de mercado. Os Atores 
sociais são vistos como aqueles que não visam tomar o poder do estado e nem visam o dinheiro, eles querem exercer influência por meio de movimentos democráticos e associações, estando ligados ao conceito de sociedade civil (CORTES, LIMA, 2012, p.39). Os Atores Estatais são aqueles que fazem parte de órgãos governamentais, que ocupam cargos de direção em organizações governamentais, ou seja, esses atores estão ligados com o Estado. Os atores de mercado visam influenciar na produção e maximizar seus lucros, suas ações políticas sempre são guiadas por esses fatores (CORTES, LIMA, 2012, p.39). Neste trabalho pretende-se mostrar a relação entre os atores sociais e os estatais, mas principalmente a influência dos atores sociais na formulação de políticas públicas.

\section{A ong Igualdade - RS}

Dando continuidade ao artigo, apresenta-se a ONG Igualdade RS, que foi o objeto de estudo deste trabalho e também pretende-se abordar a questão de gênero, visto que a Igualdade RS é uma ONG voltada para o público de travestis e transexuais.

A ONG Igualdade - Associação de Travestis e Transexuais do Rio Grande do Sul foi fundada em 1999, pela Marcelly Malta e Cassandra Fontoura, militantes dos diretos das travestis. Marcelly era enfermeira da Santa Casa na época e fazia oficinas sobre a AIDS com as travestis e transexuais que trabalhavam nas ruas de Porto Alegre. Cassandra Fontoura era profissional do sexo. A ideia de criar a ONG deveu-se principalmente à epidemia de AIDS, chamada de "câncer gay", que naquele período se espalhava rapidamente na população LGBT (Lésbicas, Gays, Bissexuais, Travestis, Transexuais e Transgêneros). A Igualdade - RS começou a atuar com muitas dificuldades, principalmente no que dizia respeito à viabilidade financeira, Cassandra então resolveu sair da Igualdade, deixando-a na responsabilidade da Marcelly. Com o passar dos anos a Igualdade foi amadurecendo e crescendo, começou a perceber que os problemas com a população de travestis e transexuais eram muito mais complexos. A AIDS era apenas um dos problemas. A partir de então, a ONG começou a se preocupar também com as questões de direitos humanos e cidadania para essa população extremamente estigmatizada e vulnerável, pois elas dificilmente conseguem trabalho formal quando assumem sua identidade de gênero, restando a prostituição como uma das únicas saídas para conseguir sobreviver. Somado a isso tem-se o fato de que no Brasil o índice de assassinatos de travestis é muito alto, devido ao forte preconceito.

No início quando a gente começou a trabalhar, a gente achou que iria trabalhar muito com a questão das doenças, a questão da AIDS, que naquela época era uma 
epidemia. Muitas travestis morriam e tal e ao longo do tempo a gente viu que não era questão apenas da epidemia da AIDS. tem a questão do preconceito e a questão dos direitos humanos né. Eu me lembro que logo no primeiro ano, quando foi oficializada a Igualdade, a gente teve 11 assassinatos de travestis né. Então a questão dos assassinatos era muito constante. Então a gente começou a ver que a AIDS e as doenças transmissíveis era uma coisa tão pequena que elas não queriam nem saber. Assim a questão dos Direitos Humanos... A gente mudou o estatuto e começamos a trabalhar mais com a questão dos direitos humanos de travestis e transexuais... (M, 63 anos).

A escolha da ONG Igualdade - Associação de Travestis e Transexuais do Rio Grande do Sul se deve principalmente a três motivos: por sua constante atuação em defesa dos direitos de seu público-alvo, ocupando um espaço cada vez maior no cenário LGBT do estado; por consistir em uma instituição que detém praticamente o monopólio da reivindicação legítima de travestis e transexuais do RS; e, por fim, pela especificidade de sua atuação (defesa dos direitos de transexuais/travestis), facilitando a investigação empírica. $\mathrm{Na}$ verdade, os dois últimos motivos se entrelaçam - tendo em vista que a Igualdade RS assume praticamente sozinha a tarefa de defesa de direitos do público-alvo em questão. Seu público é bem específico, consistindo-se em uma minoria sob todos os aspectos, inclusive dentro do movimento LGBT.

A Igualdade - RS realiza inúmeras atividades com a população de travestis e transexuais, entre elas a distribuição de preservativos à noite para as profissionais do sexo. Realiza oficinas de artesanato com as detentas da Ala Especial do Presídio Central de Porto Alegre, bem como oficinas sobre a AIDS e outras doenças sexualmente transmissíveis, além de questões que dizem respeito à saúde da população de travestis e transexuais. A ONG é importante na formulação e implementação de ações para a proteção de direitos de travestis e transexuais, agindo como um influente ator social junto ao Estado.

Como já foi mencionado, a instituição protagoniza a promoção e defesa de direitos da comunidade travesti/transexual do estado, mas também coopera com ONGs localizadas em outras unidades federativas.

O conceito de gênero jamais foi único, transformando-se com o tempo a partir das correntes e pressões de cada época.

Entende-se por gênero o conjunto de normas, valores, costumes e práticas através das quais a diferença biológica entre homens e mulheres é culturalmente significada. A categoria de gênero surgiu como uma forma de distinguir as diferenças biológica das desigualdades sócio culturalmente construídas. Gênero é um elemento constitutivo das relações sociais construídas com base nas diferenças percebidas entre os sexos. Trata-se, assim, de uma construção social, de uma forma primária de significar as relações de poder, uma vez que tais diferenças se configuram como desigualdades (BANDEIRA, 2005, p. 7). 
O caráter dicotômico permeou e permeia ainda hoje tais conceitos de gênero, por tentar enquadrar e excluir ao mesmo tempo a questão de gênero, tal lógica persiste em encaixar todos, todas e tudo em dois polos, como heterossexual/homossexual, homem/mulher, bom/mau etc. A comunidade transgênero encontra-se à margem das políticas públicas de gênero, figurando em categoria diversa, fora do predominante esquema dual.

Tal especificidade de gênero se traduz em algumas das recentes conquistas da Igualdade RS, como no caso da Carteira de Nomes Social e na galeria " $3^{\circ}$ do H", espaço no Presídio Central de Porto Alegre destinado às apenadas travestis e seus companheiros. Enquanto a primeira política representa uma iniciativa de reconhecimento da identidade de gênero, a partir de uma concepção social do conceito, a segunda, preocupa-se com a integridade física e moral das travestis que estão cumprindo pena. Em ambos os casos, está presente a tentativa de romper com uma concepção biologizante de gênero, pois as duas iniciativas priorizam o caráter social, de autorreconhecimento/autodeclaração de gênero, em detrimento de sua concepção naturalista, ou seja, estão levando em conta a identidade de gênero desses indivíduos e não apenas o sexo que eles nasceram.

A Igualdade tem sedes nos municípios de Gravataí e Guaíba/ RS, sua matriz se localiza no centro de Porto Alegre. Para os entrevistados a Igualdade RS tem muita influência na formulação de ações para a proteção de direitos dos travestis e transexuais. Nas duas passagens abaixo, eles explicam o porquê.

O jogo de cintura que a Igualdade RS tem, que às vezes carece em outras ONGs, principalmente no âmbito LGBT, é fator primordial para a influência dela, de certa forma ela detém o monopólio da reivindicação legítima da comunidade de travestis e transexuais na minha opinião. É uma rede capilarizada e é difícil que elas fiquem de fora de alguma questão que se trata de travestis e transexuais no Rio Grande do Sul (F, 24 anos).

E também:

Sempre é claro, tem coisas que a gente precisa fazer, mas dentro do nosso alcance temos bastante influência sim, tanto no meio LGBT, quanto nas políticas governamentais. A gente é sempre assim, uma das primeiras a ser chamada para ser ouvida quando tem uma novidade (L, 45 anos).

Não caberá nesse trabalho fazer uma discussão detalhada sobre o tema das políticas públicas de gênero no país, porém é importante situar que a luta por políticas mais igualitárias também atinge as mulheres, tendo seu início no período da democratização no Brasil e seguindo até os dias atuais. O principal evento que colocou o tema na agenda governamental 
foi a Conferência Mundial das Mulheres em Beijing, em 1995. Desde então aumentou a pressão internacional para a correção das desigualdades de gênero.

Com base na plataforma de ação definida na Conferência Mundial sobre a Mulher, realizada em Beijing, em 1995, e na trajetória do movimento de mulheres no Brasil (que se articula, como visto, a alterações mais abrangentes na relação EstadoSociedade ocorridas no país nas últimas décadas) constituiu-se no Brasil a agenda atual relacionada à questão de gênero. Nessa agenda, incluem-se diversas diretrizes no campo das políticas públicas (FARAH, 2004, p. 56-57).

As políticas de gênero no Brasil ainda são muito recentes, como podemos ver pela breve revisão feita acima, as mulheres ainda hoje são estigmatizadas e a população LGBT (Lésbicas, Gays, Bissexuais, Travestis, Transexuais e Transgêneros) mais ainda. O caminho para o fim das desigualdades de gênero no Brasil é longo e construído gradualmente, grande parte com a ajuda de atores sociais chave que representam e organizam as demandas dessas minorias excluídas, como fazem as ONGs.

Ao longo da pesquisa realizada para a elaboração deste trabalho, as entrevistas feitas, as visitas e as conversas com pessoas da ONG Igualdade RS e com servidores públicos foi possível entender a complexidade das relações das ONGs com o Estado. As primeiras mostraram que podiam influenciar as políticas e que eram capazes de agir juntamente com o estado, atuando em diversos setores da sociedade. Os movimentos sociais perderam força com o surgimento das organizações, mas a capacidade organizativa de grupos intervirem sobre as políticas se ampliou.

A Igualdade RS não fugiu dessa lógica. As fundadoras dessa ONG são militantes pelos direitos das travestis e transexuais, participavam dos movimentos sociais, 'davam bafão' (como elas se referem a escândalos) na frente da Prefeitura. Porém elas reconhecem que ter uma organização capaz de representar seus interesses, e ser identificada como representante legítima desses interesses, faz muita diferença na hora de reivindicar por direitos ou políticas.

Acho que é a questão da instituição, de existir um lugar onde as travestis e transexuais possam recorrer. E aí eu ligo para as secretarias, ligo para o governo e a gente vai conseguindo as coisas, pois todo mundo nos conhece, conhece nosso trabalho então fica muito mais fácil de conseguir algo...(M, 63 anos).

E também:

É fundamental, é decisiva para ter avançado em muita coisa. Acho que se não tivesse ONG, bom ou uma outra forma de organização, a gente não teria avançado tanto como avançou. Claro que ainda falta muita coisa para a gente ter direitos iguais e oportunidades iguais né, não só direitos como oportunidades iguais a maioria da população. Mas em relação com o que era a 15 anos atrás quando a Igualdade foi fundada... Nossa! Avançou muito... (A, 43 anos). 
Os militantes reconhecem a importância de haver uma organização estruturada na hora de se relacionar com o Estado, pois os atores estatais são os principais decisores sobre políticas. A ONG pode oferecer uma base organizativa para a atuação de policy communities, que tem capacidade de gerar propostas e alternativas para as políticas.

É importante salientar que a ONG Igualdade RS tem parceria com o governo e diversos órgãos públicos, como a Universidade Federal do Rio Grande do Sul, Secretarias etc, como podemos perceber abaixo e também observando o site e rede social (facebook) da Igualdade RS.

Tem, normalmente tem parceria com os governos, estadual e municipal, principalmente na área da saúde, por causa da prevenção, porque é uma ONG AIDS também né, na prevenção de DST/AIDS e direitos humanos, então nas 3 esferas, algumas parcerias institucionais, assim como a distribuição de camisinha que não depende de um projeto e outras que também não precisam, e projetos com recursos, a gente concorre por edital e temos conseguido, né (A, 43 anos)

Outro entrevistado também disse que:

Tem, tem, na própria UFRGS, o pessoal do G8 da SAJU que colabora com a ONG, parceiro, o Governo do Estado, muito ligada ao Governo do Estado, e em menor nível eu diria, não sei também, mas em outros níveis as outras ONGS, Nuances, Somos a comunidade LGBT, mas em maior parte o Governo eu diria, que causa um certo mal estar entre essa ONG (F, 24 anos)

Ao caracterizar as relações entre a ONG e o Estado, um servidor governamental salienta a importância da existência de uma organização para a formulação de propostas de ação e para a proteção de direitos.

É muito importante, pois é a ONG que traz a demanda né, elas que nos guiam para saber exatamente onde precisamos melhorar, o que precisamos fazer e para quem... Então é muito bonito esse trabalho da ONG e fundamental para o nosso trabalho também... (S, 42 anos)

Pode-se perceber que esse relacionamento entre a ONG e Estado, faz com que os atores estatais reconheçam e legitimem a própria ONG como um importante ator coletivo, que será levado em conta não somente no processo de formulação de políticas públicas, mas também em outras etapas do ciclo. Quanto mais reconhecida e influente a ONG se torna, mais relevante é o seu posicionamento na sua área de atuação, conforme podemos perceber no caso da Igualdade RS, que conseguiu alcançar essa legitimidade.

Às ONGs da área, e particularmente à Igualdade RS é atribuída a capacidade e legitimidade de representação dessa minoria, tradicionalmente excluídas de direitos de cidadania. Elas são as responsáveis por fazer a mediação entre minorias e o Estado, funcionando como uma espécie de bússola para os fazedores de políticas. Suas propostas 
oferecem um guia para os decisores políticos transformarem as ideias dessas minorias representadas pelas ONGs, em políticas públicas.

\title{
Parcerias entre a ong igualdade e o estado
}

A Carteira de Nome Social é uma política pública implementada pelo Estado do Rio Grande do Sul, que institui e reconhece o nome social das travestis e transexuais, fundamentada pelo Decreto 48.118 e pelo Decreto 49.122. O Decreto 48.118, foi publicado em junho de 2011, e estabelece o tratamento nominal, a inclusão e uso do nome social de travestis e transexuais nos registros estaduais relativos a serviços públicos prestados no âmbito do Poder Executivo Estadual. O Decreto 49.122, que tinha sido publicado em maio de 2012, institui apenas a Carteira de Nome Social para travestis e transexuais no estado do RS. É importante esclarecer que essa carteira não muda o registro civil, ela não substitui o RG original, pois para a mudança de nome na carteira de identidade é necessário que o indivíduo recorra à justiça para mudança de registro civil. Um dos problemas que a Carteira de Nome Social pode resolver é exatamente esse, pois a maioria das travestis e transexuais não tem dinheiro para iniciar um processo judicial de mudança de nome na carteira civil. A maioria das transexuais e travestis hoje, trabalha como profissionais do sexo, e dispõe de escassos recursos financeiros. A CNS permite que elas possam ser chamadas com o nome com que se identificam, não tendo de arcar com custos judiciais.

\begin{abstract}
(...) a gente mudou o estatuto e começamos a trabalhar mais com a questão dos direitos humanos de travestis e transexuais, porque hoje 98\% das travestis e transexuais trabalham na rua né, são profissionais do sexo São poucas as que tem emprego formal né. Elas são excluídas da família, são excluídas da sociedade e elas não conseguem um emprego. Não estudam na escola. A questão do preconceito... Hoje, graças a deus, temos um decreto do governador Tarso Genro, que criou a Carteira de Nome Social para as travestis e transexuais. Então hoje em dia a gente avançou... (M, 63 anos).
\end{abstract}

A Carteira de Nome Social é um documento feito pela Secretária de Segurança Pública do RS, que não tem custo algum e pode ser retirado nos mesmos locais onde é feito os demais documentos de identificação. A CNS deve ser apresentada junto com o documento de identidade, o que acabou gerando críticas sobre essa política.

A ONG Igualdade RS há muito tempo reivindica a emissão legal de um documento que tivesse o nome social de escolha das travestis e transexuais, e que pudesse ser obtido de forma gratuita. Isso porque as travestis e transexuais tinham diversos problemas ao apresentar somente a carteira civil, desde serem ridicularizadas em público, até sofrerem violência física. 
É possível perceber que nesses últimos quatro anos houve uma preocupação nos três níveis de governo, com relação às questões de gênero e a questão LGBT. O programa do governo federal, Brasil Sem Homofobia, é um exemplo disso. O governo do Estado participou na elaboração dessa política. O humor nacional (KINGDON, 1984) era favorável a isso. Havia ainda proximidade da ONG com dirigentes da gestão do governo estadual que assumiu o poder em 2011, particularmente na Secretária de Justiça e Direitos Humanos do RS. Isso facilitou o diálogo da Igualdade RS com esses atores estatais. A ONG foi a mediadora das demandas dos travestis e transexuais junto aos governantes, influindo diretamente na agenda decisória e transformando a ideia da CNS em uma política pública.

Eu trabalhava com o setor de direitos humanos e vimos que tinha uma demanda por esse procedimento, através de depoimentos da ONG Igualdade RS, ai fomos atrás, falamos com um e com outro, fizemos inúmeras reuniões até que o governador assinou um decreto e criamos junto com a Secretaria de Segurança Pública (S, 43 anos).

Pode-se perceber, que a ONG é um ator extremamente influente na formulação de políticas públicas, apresentando problemas, soluções, ideias aos governantes. A ONG trouxe a ideia e os governantes, ouviram e acataram as propostas. Havia um humor nacional favorável, ou seja, quando um grupo de pessoas compartilha das mesmas ideias em um determinado período de tempo, conforme Kingdon (1984), também foi possível constatar que havia relações próximas entre integrantes da $\mathrm{ONG}$ e atores estatais.

\section{A ala do $3^{\circ}$ do "H"}

No dia 23 de abril de 2012 foi inaugurada uma Ala no Presídio Central de Porto Alegre (PCPA), através de uma resolução do Conselho Nacional de Combate à Discriminação junto com o Conselho Nacional de Política Criminal e Penitenciária, para as travestis, transexuais e gays. Essa ala é conhecida como a ala das travestis. Situada no terceiro pavimento da galeria $\mathrm{H}$, sua criação teve uma repercussão midiática muito forte em todo o país, por se tratar de uma importante mudança no sistema prisional e um avanço nas questões de direitos humanos.

O principal problema que havia antes da criação da ala, era que as presas sofriam todos os tipos de violência física possível, tanto dos apenados como dos policiais. Os detentos não aceitavam as travestis na mesma cela dos "homens macho", conforme relato de entrevistada (M, 63 anos), e usavam isso como justificativa para agredi-las constantemente. 
(vale dizer que grande parte das travestis entrevistadas foram presas acusadas de tráfico de drogas), as travestis eram mantidas nessa galeria sob o discurso da proteção, já que em outros espaços elas poderiam ser usadas como moeda de troca, ser obrigadas a manter práticas sexuais com outros presos, tinham seus cabelos cortados e suas roupas femininas retiradas e em certas ocasiões eram usadas ainda como mulas (GOMES, 2014, p.90).

A partir disso as apenadas começaram a reivindicar um espaço separado dos demais detentos. A Igualdade, que acompanhava de perto essas violações de direitos, passou a fazer pressão junto ao governo estadual e à direção do Presídio Central para que a situação se alterasse.

(...) conversando com a Marcelly e com as próprias travestis presas, ela disse que havia muita violência com as travestis, que elas serviam de mula para o tráfico. Então eu entendo que essa ala foi criada justamente pensando na defesa delas, das travestis presas que precisam desse espaço, junto com a Igualdade. Instituição organizada da sociedade civil que aqui fora teve essa oportunidade de política, de pressionar o governo e o presídio né, para a criação dessa ala, nos moldes do que já existia em BH, pois a Marcelly já sabia, já tinha conhecimento dessa ala em BH e então ela pensou que aqui podia ser parecido (G, 24 anos).

A partir das pressões, a direção do Presídio primeiramente tentou separá-las dos demais presos. Porém isso provou resistências das travestis. A intervenção realizada de forma autoritária, sem negociação prévia causou revolta, pois algumas travestis não queriam deixar seus namorados. Mesmo com toda a violência, algumas tinham criado laços afetivos e amorosos. Foi nesse momento que o Presídio contatou a Igualdade RS, para dialogar com as presas a fim de encontrar uma solução para o conflito. A Igualdade RS iniciou um trabalho com as apenadas que durou nove meses, nesse processo realizou oficinas discutindo a violência dentro do sistema carcerário, a questão dos direitos humanos e conversas sobre a situação na qual se encontravam, que medidas poderiam ser adotadas naquelas circunstâncias, de maneira a melhorar a situação das travestis no presídio. O trecho da entrevista abaixo, ilustra a situação.

(...) teve esse momento de pressão da Igualdade, mas também teve um momento de pedido da direção do presídio para que a Igualdade fosse e acompanhasse as travestis e esse acompanhamento das travestis presas ele supunha um espaço exclusivo para que elas não pudessem mais sofrer violências dos homens... (G, 24 anos).

Após nove meses de trabalho, chegou-se à conclusão que a melhor alternativa era o Presídio disponibilizar uma cela que abrigasse tanto as travestis como seus companheiros. O Presídio tinha uma ala vazia que foi utilizada para a realização desse objetivo. Abaixo temos uma fala que ilustra o processo de implantação da Ala. 
(...)e aí que se encontrou a galeria A, que era uma galeria que estava lá vazia. Ela foi pintada, reformada e arrumada. E começou-se esse trabalho, então para que as travestis aceitassem essa possibilidade de serem transferidas para essa galeria e ficar separada dos demais detentos. Isso foi bem difícil... (T, 59 anos)

A nova Ala foi inaugurada em abril de 2012, nesse dia compareceram diversas autoridades públicas do Estado do Rio Grande do Sul e também do Ministério de Direitos Humanos da Presidente da República. As travestis também participaram da inauguração, bem como a mídia local. A notícia teve grande repercussão não somente no Estado, mas também em todo o país.

\section{Considerações finais}

O presente trabalho teve por objetivo contribuir para o entendimento de como são formuladas políticas públicas, mais especificamente explorar a noção de que atores sociais podem participar nesse processo a partir das ONGs. A ampliação dos direitos das minorias, particularmente as minorias estigmatizadas, torna-se importante para entender como ideias e propostas provenientes da sociedade civil, de organizações que representam essas minorias, transformam-se em políticas, identificando os tipos que influenciam nesse processo, como era o foco principal deste trabalho.

O movimento feminista estava na origem das demandas por direitos e por políticas de gênero, mas atualmente existe um leque de outros movimentos com uma pauta de demandas variada, como é o caso dos grupos envolvidos com a causa LGBT (Lésbicas, Gays, Bissexuais, Travestis, Transexuais e Transgêneros). Dessa maneira o Estado se viu pressionado a atender às exigências dessas minorias excluídas, promovendo políticas públicas, que mesmo que tenham tido um desenvolvimento tardio, devido à dramaticidade das condições em que viviam esses grupos, hoje oferecem algum tipo de proteção e de garantia de direitos.

Este trabalho mostra que a Política da Carteira de Nome Social e a Ala do Terceiro 'H' no Presídio Central de Porto Alegre, são ações de políticas públicas que representam avanços na proteção de direitos de um segmento social profundamente estigmatizado. Argumenta-se que esse avanço se deve principalmente à ação de atores da sociedade civil, organizados em uma ONG de defesa de direitos que teve capacidade de se articular com atores governamentais para fazer com que suas ideias e problemas ingressassem na agenda dos governantes. Os próprios atores estatais reconheceram a Igualdade RS como um importante 
parceiro na formulação de políticas públicas e, também, na implementação, no caso da Ala do Terceiro 'H' no Presídio Central.

As organizações não governamentais são um importante mecanismo na formulação de políticas públicas, seja porque muitas delas representam minorias, seja pela porque realizam mediações entre a sociedade civil e o Estado. No caso da Igualdade RS, a organização agia como um importante ator coletivo no que diz respeito a apresentar soluções e alternativas para os governantes destinadas a beneficiar travestis e transexuais.

Particularmente quando analisamos Ala do Terceiro ' $H$ ' no Presídio Central, percebemos que, por vezes, é difícil observar de forma rígida a separação entre as etapas do ciclo das políticas públicas. A ação para a proteção de direitos das travestis e seus companheiros no Presídio Central de Porto Alegre mostrou a necessidade da colaboração dos integrantes da Igualdade RS, não apenas para colocar a questão na agenda, mas também para viabilizar a implementação da ação. A análise das entrevistas demonstrou que a ONG Igualdade RS que inicialmente havia participado apenas das fases iniciais do ciclo da política - influiu na formação da agenda, participou na formulação da política -foi chamada a participar na fase de implementação. A direção do Presídio Central percebeu que sem o auxílio da ONG a criação da Ala seria impossível, dada a resistência das presas à mudança. Embora o foco do trabalho fosse sobre a formação da agenda, observou-se que a ONG foi importante também na formulação da política e na sua implementação.

No caso da Carteira de Nome Social, a separação entre as etapas do ciclo das políticas é mais nítida, até porque a implementação da decisão de criar a carteira é mais simples, pois trata-se apenas de elaborar um documento. Os conflitos são anteriores a decisão, que uma vez tomada é de fácil implementação. O documento ofereceu às travestis e transexuais o direito de serem chamadas com o nome que elas se identificam. A crítica é que a Carteira de Nome Social para ser considerada válida precisava ser apresentada junto com o documento civil original. A legislação não permite a troca do nome sem ser iniciado um processo judicial, a CNS foi a solução encontrada para que fosse possível obter um 'nome social' de maneira gratuita. Apesar das críticas, a CNS é uma alternativa para quem não tem como arcar com os custos de uma mudança no nome civil.

ONGs como a Igualdade RS são um importante ator coletivo no momento de construir problemas, apresentar demandas e construir soluções a serem apresentadas a atores estatais. Em suma participam da relação entre Estado e sociedade como mediadores das demandas 
sociais frente aos governos. Em alguns casos até mesmo a implementação de políticas em instituições estatais, como no caso do Presídio Central de Porto Alegre, depende de sua colaboração.

\section{Referências bibliográficas}

ALEXANDER, Jeffrey C. "Ação coletiva, cultura e sociedade civil - Secularização, atualização, inversão, revisão e deslocamento do modelo clássico dos movimentos sociais". Revista Brasileira de Ciências Sociais, São Paulo, v.13, n37, jun. 1998.

AVRITZER. Leonardo. "Sociedade civil e Estado no Brasil: da autonomia à interdependência política”. Opinião pública, Campinas, v.18, n2, nov. 2012.

BANDEIRA, Lourdes. "Fortalecimento da Secretaria Especial de Políticas para as Mulheres Avançar na Transversalidade da Perspectiva de Gênero nas Políticas Públicas”. Observatório Brasil da Igualdade de Gênero, 2005.

CAPELLA. Ana Cláudia. "Formação na Agenda Governamental: Perspectivas Teóricas". In: XXIX Encontro anual da ANPOCS (Associação Nacional de Pós-Graduação e Pesquisa em Ciências Sociais), GT19 - Políticas Públicas. Caxambu-MG, 2005.

COHEN, Jean L. "Sociedade civil e globalização: repensando categorias". Dados, Rio de Janeiro, v.46, n.3, 2003

CORTES, Soraya Vargas. LIMA, Luciana Leite. "A contribuição da sociologia para a análise de políticas públicas”. Lua Nova: Revista de Cultura e Política, São Paulo, n87, 2012.

COUTINHO, Carlos Nelson. Gramsci. Um estudo sobre seu pensamento político. Nova edição ampliada. Rio de Janeiro: Civilização Brasileira, 2007.

FARAH, Marta Ferreira Santos. "Gênero e políticas públicas”. Revista Estudos Feministas, Florianópolis, v.12, n1, jan/abr. 2004.

GOHN, Maria da Glória. "Movimentos sociais na contemporaneidade". Revista Brasileira de Educação, Rio de Janeiro, v.16, n47, mai/ago. 2011.

GOMES, Guilherme. Travestis e prisões: a experiência social e a materialidade do sexo e do gênero sob o lusco-fusco do cárcere. 2014. Dissertação (Mestrado em Serviço Social) Pontifícia Universidade Católica do Rio Grande do Sul, Porto Alegre.

KINGDON, J. Agendas, Alternatives, and Public Policies. Boston: Little, Brown. 1984

LOWI, Theodore J. "Four Systems of policy, politics, and choice". Public Administration Review, v.32, n4, p.298-310, jul/ago. 1972.

MALHOTRA, Naresh K. Pesquisa de marketing: uma orientação aplicada. 4ed. Porto Alegre: Bookman, 2006. 720 p.

SCHMIDT, João Pedro. "Para entender as políticas públicas: aspectos conceituais e metodológicos". In: REIS, Jorge Renato dos; LEAL, Rogério Gesta. Direitos sociais e 
políticas públicas: desafios contemporâneos. Santa Cruz do Sul: UDUNISC, 2008. Tomo 8. P. 2307-2333.

SOUZA, Celina. "Políticas públicas: uma revisão da literatura". Sociologias, ano 8, n16, p.20-45, jul/dez. 2006.

TOURAINE, Alain. The Voice and the Eye: An Analysis of Social Movements. New York: Cambridge University Press, 1981.

Recebido em: Agosto de2017 Aprovado em: Dezembro de 2017 